\title{
PERSPECTIVAS INTERCULTURAIS SOBRE O LETRAMENTO
}

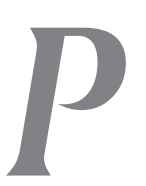

or meio de relatos dos usos e significados do letramento em outros lugares e épocas, gostaria de situar a discussão sobre o letramento contemporâneo numa perspectiva mais ampla. Ao contemplar práticas de letramento em contextos tão variados quanto o sudeste asiático no século XV, um atol do Pacífico do Sul nos dias de hoje e recentes relatos da Nova Guiné, Madagascar e Filadélfia, espero demonstrar a variedade e complexidade dos letramentos e desafiar algumas suposições dominantes sobre letramento em nossa própria cultura. Quero contemplar o letramento, primeiramente, fora do arcabouço da educação em que se vê invariavelmente inserido nas discussões nos Estados Unidos; oferecer análises qualitativas em vez de quantitativas; e situar as práticas de letramento no contexto do poder e da ideologia, e não como uma habilidade neutra, técnica.

Precisamos começar, acredito, tentando tomar consciência da linguagem que usamos e das perguntas que fazemos. $\mathrm{O}$ poder de

King's College London - UK. Tradução de Marcos Bagno.

1 Agradecemos ao autor e à John Benjamins Publishing Company, Amsterdam/Philadelphia $<w w w . b e n j a m i n s . c o m>$, por permitirem, gentilmente, a tradução do artigo Cross-cultural perspectives on literacy, originalmente publicado em VERHOEVEN, Ludo (Ed.). (1994). Functional Literacy: theoretical issues and educational implications; Amsterdam/Philadelphia, John Benjamins, p. 95-111. [Nota dos organizadores da seção temática deste número da Revista de Filologia e Lingüística Portuguesa.] 
STREET, Brian. Perspectivas interculturais sobre o letramento.

definir e de nomear é em si mesmo um dos aspectos essenciais dos usos do letramento, de modo que precisamos ser ainda mais cuidadosos acerca dos termos ao abordar o próprio letramento. De acordo com isso, proponho alguns conceitos-chave como um tipo de esquema no qual encaixar descrições do letramento em prática. Prefiro, antes de mais nada, falar de práticas de letramento do que de "letramento como tal". Existem vários modos diferentes pelos quais representamos nossos usos e significados de ler e escrever em diferentes contextos sociais e o testemunho de sociedades e épocas diferentes demonstra que é enganoso pensar em uma coisa única e compacta chamada letramento. A noção de que a aquisição de um letramento único e autônomo terá consequiências pré-definidas para os indivíduos e as sociedades provou ser um mito, quase sempre baseado em valores específicos culturalmente estreitos sobre o que é propriamente o letramento (Graff, 1979; Grant, 1986; Gee, 1990; Street, 1990). Prefiro trabalhar com base no que chamo de modelo "ideológico" de letramento, o qual reconhece uma multiplicidade de letramentos; que o significado e os usos das práticas de letramento estão relacionados com contextos culturais específicos; e que essas práticas estão sempre associadas com relações de poder e ideologia: não são simplesmente tecnologias neutras (Street, 1985, 1993).

\section{$L E T R A M E N T O \in$ IDENTIDADE}

Gostaria de estender algumas dessas propostas para argumentar que as práticas de letramento são constitutivas da identidade e da pessoalidade (personhood). O que quero dizer com isso é que, quaisquer que sejam as formas de leitura e escrita que aprendemos e usamos, elas são associadas a determinadas identidades e expectativas sociais acerca de modelos de comportamento e papéis a desempenhar. Por exemplo, o trabalho de Rockhill (1987) sobre gênero e letramento nos Estados Unidos mostrou que as mulheres hispânicas, tentando livrar-se da pobreza e do jugo de homens dominadores e frequientemente violentos, constroem uma imagem 
Filol. lingüíst. port., n. 8, p. 465-488, 2006.

de uma identidade alternativa para si mesmas que associam com a aquisição de um novo letramento. Elas, de fato, já praticam consideráveis habilidades de letramento na administração do lar e nas relações com os órgãos do governo, escolas, etc., mas esse letramento doméstico é marginalizado e é associado a baixo status. $\mathrm{O}$ tipo de letramento oferecido por cursos em colleges, por outro lado, é associado a status superior e às ocupações e identidades a que elas aspiram: os tipos de imagens exibidas no cinema e nas revistas, representações da mulher "profissional", a secretária, a mulher que é "alguém” (Rockhill, 1987b). Horsman (1989), de igual modo, escrevendo sobre mulheres nas províncias marítimas do Canadá, observa que aqueles que oferecem cursos para elas supõem que o letramento é associado a identidades femininas específicas: embora as próprias mulheres vejam o letramento como uma saída para as obrigações caseiras e domésticas, os programas frequientemente fazem as lições de letramento retroceder para casa, reinserindo as mulheres em sua identidade doméstica. Os tipos de habilidades de letramento oferecidos são aqueles associados a ocupações supostamente apropriadas para as mulheres: tarefas domésticas, "cuidados" ("caring"), muitas vezes centradas nos filhos, uma identidade bastante diferente daquela em vista da qual as mulheres inicialmente recorreram ao programa de letramento.

\section{PESSOALIDADE $\in$ LETRAMENTO ATRAVÉS DAS CULTURAS}

Existe uma literatura antropológica sobre a noção de "pessoalidade" (personhood) em diferentes culturas que pode ser útil neste contexto. Kirkpatrick, por exemplo, sugere que a "pessoalidade é mais bem vista como um campo que é ideologicamente estruturado em qualquer sociedade" (1983, p. 1). Com isso ele quer dizer, não que a pessoa é determinada por instituições dominantes ou de-cimapara-baixo (como em conceitos anteriores de "ideologia", cf. Eagleton, 1990), mas que é um "lugar de articulação de componentes ideológicos dominantes e subordinados”. Há uma competição pe- 
STREET, Brian. Perspectivas interculturais sobre o letramento.

las definições apropriadas de pessoa, e não um único "conceito totalizador como o indivíduo", com o qual operam várias sociedades (e teóricos) ocidentais. Kirkpatrick oferece um útil sumário dos diferentes modos pelos quais a pessoa tem sido representada tanto na literatura acadêmica quanto na ideologia popular. A pessoa foi vista, por Mauss, por exemplo, "como um termo básico que organiza a moralidade e uma categoria fundamental da mente humana"; por Hallowell como "um meio importante para a formulação e produção cultural da autoconsciência"; e por Geertz como "um modelo de e para ação, central para o entendimento tanto da ordem social quanto do processo social" (Kirkpatrick, 1983, p. 1). Geertz, por exemplo, segundo Kirkpatrick, deixa evidente "a multifuncionalidade da pessoa”. Diferentes concepções culturais são invocadas em diferentes contextos a respeito da natureza e das potencialidades da pessoa. Em muitas sociedades ocidentais, a pessoa está ligada à idéia de um "indivíduo" único, persistente e integral, como se essa persona operasse ao longo de todos os contextos. Na Polinésia, em contraste, os variados significados da pessoalidade em contextos diferentes são mais evidentes. Os dados interculturais, portanto, sugerem que a "noção de pessoa sustentada na sociedade é inevitavelmente complexa e ambígua" e diferentes facetas da pessoa são invocadas para diferentes propósitos e contextos. Apesar dessa variação, porém, num dado meio social "os construtos de pessoa retêm um núcleo de valores e significados para os participantes sociais". Particularmente, os julgamentos de pessoas e eventos como "morais" são muitas vezes enfocados nas noções de pessoalidade: o que é comportamento adequado, o que é/não é humano; como nós e eles são classificados em alguma ordem de mundo universal; todos esses procedimentos ordenadores fazem uso central do conceito de pessoa.

Gostaria de desenvolver esta análise em duas direções com o propósito de dar conta do letramento. Primeiramente, os usos e significados de letramento em diferentes sociedades são semelhantes aos usos e significados do conceito de pessoa, na medida em que ambos representam o que Kirkpatrick chama campos, nos quais as es- 
Filol. lingüíst. port., n. 8, p. 465-488, 2006.

truturas dominantes e outras estruturas ideológicas são visíveis (1983, p. 12). Em segundo lugar, existe frequientemente uma relação fundamental entre os campos ideológicos de pessoalidade e letramento. O que vem a ser uma pessoa, a ser moral e a ser humano em contextos culturais específicos é muitas vezes representado pelo tipo de práticas de letramento em que a pessoa está comprometida. Isso é enfatizado pelas maneiras como, durante o Ano Internacional da Alfabetização, as organizações (unEsco inclusive) acabaram por associar letramento com a idéia de uma pessoa plenamente humana, brilhando em contraste com o espaço escuro do "analfabetismo". Eu gostaria de sugerir que isso é característico dos modos como letramento e pessoalidade estão interligados em diversos discursos culturais e serve para nos lembrar que a aquisição do letramento envolve mais do que habilidades meramente técnicas.

Esses princípios gerais são aplicados por Besnier (1991) num estudo específico sobre "Letramento e noção de pessoa" no atol de Nukulaelae, no Pacífico, onde ele empreendeu trabalho de campo antropológico. "A pessoa em Nukulaelae", diz ele, "é considerada como um complexo sistema de 'significados' mais ou menos autônomos de uiga" que aparecem em diferentes contextos e podem estar em conflito entre si. "Cada aspecto da pessoa é relacionado de modos complexos a experiências emocionais, dinâmicas interacionais e papéis emocionais particulares. Na etnopsicologia de Nukulaelae, a noção de self como lugar da experiência psicológica e a de pessoa como ator social estão inter-relacionadas" (1991, p. 19). A relevância disso para nossas preocupações presentes é que em Nukulaelae "o letramento mesmo é visto como um elemento importante na própria definição de pessoa, na medida em que ser capaz de ler e escrever é pressuposto na caracterização de uma pessoa socialmente competente. O letramento, portanto, está constitutivamente relacionado com a pessoalidade". Nesse contexto, há dois letramentos diferentes, o associado com o pronunciamento de sermões e o associado com a redação de cartas, e cada um envolve diferentes aspectos de pessoalidade e identidade. As cartas pessoais são associadas com afeto e 
STREET, Brian. Perspectivas interculturais sobre o letramento.

situam o indivíduo num sistema socioeconômico de generosidade, sociabilidade e preocupação para com os parentes mais jovens (o que suscita admoestações e aconselhamento moral). "A pessoa tal como representada nas cartas, por outro lado, é uma entidade vulnerável à mercê da experiência emocional e das circunstâncias da vida. Os sermões, por seu turno, trazem à tona o autoritarismo e a assertividade e enfatizam assimetrias de poder, conhecimento e moralidade entre o escritor-pregador e a audiência” (p. 20). Os pregadores de sermão arengam sua audiência; os autores de cartas expressam empatia.

Diferentes letramentos, portanto, são associados a diferentes pessoalidades e identidades. Conjuntos semelhantes de associações podem ser vistos nesta cultura, uma vez reconhecida a importância do letramento para tais processos. Quando frequientamos um curso ou uma escola, ou nos envolvemos num novo quadro institucional de práticas de letramento, por meio do trabalho, do ativismo político, dos relacionamentos pessoais, etc., estamos fazendo mais do que simplesmente decodificar um manuscrito, produzir ensaios ou escrever com boa letra: estamos assumindo - ou recusando - as identidades associadas a essas práticas. A idéia de que as práticas de letramento são constitutivas de identidades fornece-nos uma base diferente - e eu argumentaria: mais construtiva - para compreender e comparar as práticas de letramento em diferentes culturas, alternativa à ênfase corrente numa simples dicotomia letramento/iletramento, em necessidades educacionais como inevitavelmente endêmicas ao letramento e no tipo de letramento associado com uma pequena subcultura acadêmica, com sua ênfase no texto ensaístico e na identidade típica a ele associada.

\section{LETRAMENTOS COMO LUGARES DE NEGOCIAÇÃO}

Embora eu pareça estar argumentando que as práticas de letramento podem nos posicionar, também gostaria de considerar de que modo os letramentos podem ser lugares de negociação e de 
Filol. lingüíst. port., n. 8, p. 465-488, 2006.

transformação. Era comum nas ciências sociais, até recentemente, encarar a sociedade como, antes de mais nada, um processo de dominação de cima para baixo, com a ideologia servindo os propósitos de um grupo dominante e o resto como vítimas passivas ou relutantes. Recentemente, essa perspectiva foi substituída por outra que dá maior reconhecimento ao agenciamento* (agency), ao modo como as pessoas em diferentes posições rejeitam e negociam as posições que aparentemente lhe são atribuídas. As implicações disso para os estudos do letramento são consideráveis: a aquisição de um conjunto particular de práticas de letramento, enquanto claramente associada a identidades culturais particulares, pode de fato ser um foco para transformação e desafio. As mulheres hispânicas de Rockhill não eram simplesmente vítimas passivas dos estereótipos de mulheres e de letramento na mídia - elas usavam suas idéias sobre novas formas de letramento para resistir à dominação de maridos e filhos que tinham, de novo, estereótipos diferentes, para se opor aos quais as mulheres tinham de lutar duramente. $\mathrm{O}$ resultado dessas lutas entre diferentes versões de identidade e de letramento tem de ser analisado em cada caso: ele não pode ser interpretado como um produto direto da aquisição do letramento como tal. Esse reconhecimento leva a uma visão mais profunda do tipo de letramento que é dominante em nossa própria sociedade. De uma perspectiva intercultural, fica claro que um conjunto de práticas de letramento particular e culturalmente definidas são dominantes na sociedade americana, mas de dentro da sociedade a questão de por que tem de ser assim raramente está na agenda. Essa foi, contudo, a pergunta feita por Hirsch e Bloome, entre outros, ao surgir o espectro de uma crise de letramento na América do Norte. $O$ debate que eles instigaram tem consciência do caráter ideológico dos conflitos sobre o letramento apropriado: fica bastante explícito no trabalho de Hirsch, e especialmente em sua lista do

N. T.: Usamos aqui o termo agenciamento de acordo com as duas primeiras acepções dadas ao verbo agenciar no dicionário eletrônico Aurélio 2.0: "1. Tratar (de negócios) como representante ou agente; 2 . Tratar ou cuidar de; lutar por; cavar". 
STREET, Brian. Perspectivas interculturais sobre o letramento.

"que todo americano deveria saber", que o conflito sobre que letramento deveria ser o dominante já terminou.

No entanto, o fato de uma forma cultural ser dominante é, no mais das vezes, disfarçado por trás de discursos públicos de neutralidade e tecnologia nos quais o letramento dominante é apresentado como o único letramento. Quando outros letramentos são reconhecidos, como, por exemplo, nas práticas de letramento associadas a crianças pequenas ou a diferentes classes ou grupos étnicos, eles são apresentados como inadequados ou tentativas falhas de alcançar o letramento próprio da cultura dominante: exige-se então a atenção remediadora, e os que praticam esses letramentos alternativos são concebidos como culturalmente desprovidos. Dentro do campo da linguiística já se reconheceu claramente que existe uma grande variedade de formas de língua - dialetos, registros, crioulos, etc. - e que o padrão é, ele também, apenas mais uma "variedade". O modo como um padrão alcança esse status foi posteriormente enfatizado pela cunhagem da expressão língua dominante (Grillo, 1989), que deixa explícito que se trata de poder e de luta pela dominação, mais do que de um processo natural da emergência do "melhor" como padrão. Eu gostaria de sugerir que adotássemos, de igual modo, a noção de letramento dominante a fim de salientar a extensão com que o letramento que é tratado como o padrão é apenas uma variedade entre muitas e que a questão de como ele se tornou o padrão é igualmente uma questão de poder. Isso implica, portanto, que nos refiramos a variedades de letramento tal como nos acostumamos a falar de variedades de língua. De que modo o letramento dominante marginaliza outras variedades, afirma sua própria dominação e disfarça sua própria base de classe e de cultura são questões que raramente têm sido levantadas no campo do letramento: o desenvolvimento de alguns dos conceitos que proponho aqui ajudará, espero, a pôr essas questões na ordem do dia e a facilitar a pesquisa e a investigação nessas áreas negligenciadas.

John Ogbu, conhecido pesquisador em educação, sugeriu recentemente uma definição de letramento ainda mais estreita do que 
Filol. lingüíst. port., n. 8, p. 465-488, 2006.

a que tenho criticado até agora, mas que provavelmente representa a visão dominante, ao menos nos círculos educacionais: "Defino letramento como a capacidade de ler e escrever e calcular na forma ensinada e esperada na educação formal... [letramento portanto é] sinônimo de desempenho acadêmico" (Ogbu, 1990). Contra essa noção de letramento, de base educacional e acadêmica, eu gostaria de apresentar uma descrição de uma forma de letramento no sudeste asiático que oferece uma base diferente para começarmos nossa consideração das práticas de letramento:

O velho alfabeto indonésio ka-ga-nga não era ensinado em nenhuma escola e não tinha nenhum valor, quer vocacionalmente, quer na leitura de qualquer literatura religiosa ou secular estabelecida. A explicação dada para sua persistência era o costume local do manjan, um jogo de galanteio por meio do qual rapazes e moças se reuniam às tardes e os jovens arremessavam quadrinhas sugestivas [pantuns] escritas no velho alfabeto às jovens de quem gostavam. (Reid, 1989, p. 218)

Há mais nas práticas de letramento do que sonha a filosofia ocidental.

\section{LETRAMENTO $\in$ VARIAÇÃO CONTEXTUAL}

\section{Letramento em contextos não-europeus}

O testemunho do sudeste asiático fornece mais material para desafiar a visão estreita de letramento. As práticas de letramento, ao que parece, estavam difundidas na era que precedeu o impacto ocidental. Não tratava-se de uma questão de elite nem de interesses comerciais, mas de uma variedade de costumes e práticas locais. A escrita nas Filipinas no século XVI, por exemplo, não servia a nenhum propósito religioso, jurídico ou histórico, mas era usada apenas para redigir notas e cartas. Em outros lugares, as mulheres usavam a escrita ativamente para trocar bilhetes e registrar dívidas, enquanto no sul de Sumatra, ainda em 1930, altas proporções da população empregavam o letramento para concursos de galanteio poético 
STREET, Brian. Perspectivas interculturais sobre o letramento.

(Reid, 1988). A chegada do islã e do cristianismo teve o efeito de reduzir os índices de letramento, particularmente entre as mulheres, ao restringir a escrita aos domínios masculino, sacramental e monástico. Nas Filipinas, o conhecimento das escritas tradicionais desaparecera depois de um século de cristianização, e um destino semelhante se abateu sobre as escritas pré-islâmicas na Malásia e partes de Sumatra. Esses exemplos levantam questões novas sobre a participação relativa dos sexos nos usos do letramento e sobre os usos do letramento. Uma vez que o letramento não era ensinado em nenhuma instituição formal e não tinha nenhum valor vocacional ou religioso, sua transmissão tendia a ser sobretudo da responsabilidade das mães e dos irmãos mais velhos. O contexto social do aprendizado do letramento, portanto, facilitava os usos do letramento pelas mulheres, que empregavam elas mesmas as habilidades de letramento no contexto não apenas dos "concursos de galanteio poético" mencionados acima, mas também na troca de bilhetes, no registro de dívidas e outros assuntos comerciais que eram do domínio feminino (Reid, 1988). Por conseguinte, as taxas de alfabetização entre as mulheres eram tão altas quanto entre os homens e alguns viajantes encontraram-nas até mais elevadas (Reid, 1988, p. 219). O advento dos ocidentais, com suas instituições religiosas dominadas pelos homens, alterou o equilíbrio na direção do letramento masculino e da escolarização formal. Esse desequilíbrio caracteriza muitos relatos das práticas de letramento segundo o sexo no mundo contemporâneo: frequientemente a modernização e as suposições embutidas na teoria educacional ocidental - e não a cultura tradicional ou o "atraso" - estão por trás das desigualdades que observamos.

Durante o último século, um bom número de sociedades que anteriormente tinham pouca ou nenhuma familiaridade com o letramento passaram a usar a leitura e a escrita como parte de seu repertório comunicativo. Questões sobre o "impacto" do letramento sobre tais povos ou suas "consequiências" para a cognição e o desenvolvimento social tenderam a supor um único letramento - o 
dos ministrantes - e um único processo previsível - o da transformação de passivos "iletrados" em letrados. Kulick e Stroud descobriram, ao ler a literatura sobre transferência de letramento, que "é frequientemente difícil escapar da conclusão de que os seres humanos são basicamente objetos passivos que ficam afetados pelo letramento de modos dos quais não têm consciência plena ou que não podem controlar" (Kulick \& Stroud, 1990). Os responsáveis por ministrar o letramento tenderam a tratar os povos indígenas como tratariam alunos de escola, debatendo se estavam "prontos" para o letramento, se deveriam ter acesso a ele e que problemas estavam associados com seu "impacto". De um ponto de vista pedagógico, o processo é visto como a aquisição de específicas habilidades técnicas e o aprendizado das convenções e suposições sobre letramento sustentadas pelos professores.

Minha opinião é a de que precisamos assumir uma visão menos paternalista e menos estreitamente pedagógica do processo: Kulick e Stroud, por exemplo, afirmam: "em vez de sublinhar como o letramento afeta as pessoas, queremos mudar de lado e examinar como as pessoas afetam o letramento". Eles querem demonstrar "como os indivíduos numa sociedade recém-letrada, longe de serem passivamente transformados pelo letramento, em vez disso aplicam ativa e criativamente as habilidades de letramento para atender a seus próprios propósitos e necessidades"; como eles "se apoderam" do letramento, em vez de qual o "impacto" do letramento sobre eles. Um novo letramento é incorporado às convenções e conceitos acerca da comunicação já existente na cultura receptora - os "sujeitos" não são "tábuas rasas" como tantas campanhas de desenvolvimento da alfabetização parecem supor (Street, 1987). Isso também revela como os processos de letramento não podem ser entendidos simplesmente em termos de escolarização e pedagogia: eles são parte de instituições e concepções sociais mais abrangentes.

Kulick e Stroud analisam as adaptações ao letramento que observaram numa aldeia rural de Papua-Nova Guiné recém-alfabeti- 
STREET, Brian. Perspectivas interculturais sobre o letramento.

zada. Demonstram como as idéias locais de self e outras estão articuladas e são reforçadas por meio de uma ênfase em dimensões particulares do uso da língua oral. Várias convenções empregadas na oralidade, particularmente no pronunciamento de discursos, são transportadas para as formas escritas: a evitação de 'hed' - para não parecer agressivo e autocentrado - e a ênfase em 'save' - um conceito complexo que indica ao mesmo tempo abertura ao conhecimento e sensibilidade para com os interesses dos outros. Algumas das novas formas escritas que emergiram sob influência dos missionários foram obrigadas a se conciliar com esses valores e convenções, levando a resultados não necessariamente previstos pelos próprios missionários.

O exemplo citado mais acima do atol de Nukulaelae, no Pacífico Sul, também mostra como os novos letramentos podem ser assimilados a convenções comunicativas preexistentes, como no caso da Nova Guiné, e também os modos como o repertório pode se expandir e alterar formas locais de comunicação (Besnier, 1988). De novo, a introdução do letramento por missionários acarretou a adaptação de seus propósitos aos dos ilhéus. $\mathrm{O}$ propósito primeiro da produção de letramento em Nukulaelae é escrever cartas. As cartas de Nukulaelae são enviadas a parentes em atóis vizinhos, e servem a uma variedade de funções: monitorar o intercâmbio econômico; informar os parentes de acontecimentos na família; e aconselhar as pessoas mais jovens. Permeando cada aspecto das cartas está uma forte ênfase na aberta expressão do afeto, de uma natureza geralmente não encontrada em outras áreas da vida social de Nukulaelae. A expressão aberta de certos tipos de afeto nas cartas, enquanto na comunicação oral os ilhéus normalmente expressam o afeto por meios encobertos, sugere que as suposições tradicionais sobre a associação do meio de comunicação com expressões particulares de emoção ou desapego não podem ser generalizadas: as maneiras como o afeto é veiculado no repertório comunicativo variam segundo as culturas e segundos os meios, e não podemos supor que na medida em que as pessoas adquirem o letramento, adquirirão 
Filol. lingüíst. port., n. 8, p. 465-488, 2006.

também as convenções para usar o repertório conforme a expectativa da cultura ministrante. A detalhada etnografia de Besnier dos usos e significados particulares do letramento em Nukulaelae constitui um desafio às suposições ocidentais tradicionais acerca do uso da escrita para fins distanciados e não-emocionais e não para veicular o sentimento.

Um relato recente da introdução de novos sistemas educacionais numa aldeia Zafiminary na remota região oriental de Madagascar enfatiza ainda a necessidade de ver a educação num contexto mais amplo e de ver nossas próprias práticas educacionais como específicas de uma cultura, e não universais (Bloch, 1992). O papel do letramento no processo da transferência educacional deve ser entendido, sugere Bloch, em termos de teorias culturais de conhecimento implícitas. Entre os Zafiminary, os usos e significados do letramento estão vinculados a crenças sobre o corpo, sobre o amadurecimento e sobre a natureza do mundo vivo, questões que a princípio aparentemente nada têm que ver com letramento. $\mathrm{O}$ próprio caráter remoto e insólito da aldeia que Bloch descreve tem a intenção de fazer ver aos leitores ocidentais o quanto suas expectativas sobre o papel e a importância da escolarização e do letramento são culturalmente determinadas. Porque aqui a resposta ao desenvolvimento da escolarização por parte do governo e da igreja é bastante diferente da norma nos ambientes educacionais ocidentais. Bloch descreve as práticas diárias associadas à escolarização na aldeia de Mamolena, onde existe uma aparente contradição entre a evidente irrelevância para a vida diária daquilo que é ensinado e, todavia, o respeito pelo ensino e pelo valor do letramento. A explicação, sugere ele, reside na associação de diferentes formas de conhecimento com diferentes estádios da vida, com diferentes códigos comunicativos e com preocupações culturais mais amplas acerca do corpo, do sexo e do amadurecimento. $\mathrm{O}$ conhecimento escolar é assimilado a essas concepções locais, em vez de ter simplesmente um "impacto" sobre elas. A noção da sabedoria dos mais velhos como fixada, não-funcional, acima e além das preocupações práticas quotidianas e, portanto, merecedora de 
STREET, Brian. Perspectivas interculturais sobre o letramento.

respeito, porém, de diversas formas, irrelevante, oferece um quadro para conceitualizar o novo conhecimento escolar: esse também é praticamente irrelevante para os propósitos locais, mas digno do status de conhecimento de mais velhos. Problemas ocorrem quando esse conhecimento escolar é dado aos jovens em vez de aos velhos, mas Bloch mostra como tais dificuldades são superadas por meio de uma série de sutis ajustes locais. As cartas, por exemplo, são escritas principalmente por homens jovens, mas a autoridade associada a elas é "assumida" pelos mais velhos, que tratam os jovens como meros escribas, canais por meio dos quais os velhos continuam seus discursos de autoridade. Como nos exemplos dados por Kulick e Stroud e por Besnier, as convenções comunicativas locais determinam como as novas técnicas comunicativas associadas ao letramento e à escolarização são realmente empregadas. Bloch conclui que, em contraste com as expectativas embutidas no modelo de letramento autônomo, "nem a escrita nem a escolarização fizeram qualquer diferença significativa nos princípios organizativos básicos que governam a avaliação do conhecimento; ao contrário, o letramento e a escolarização foram usados para reforçar padrões existentes". Isso não quer dizer que tais sociedades são sempre meramente conservadoras e que novos letramentos também não alteram convenções existentes, como os dados de Besnier ilustram: de fato, foi esse o caso em outras partes de Madagascar, como observa Bloch. Mas tais diferenças têm de ser explicadas em termos de condições locais e requerem um sentido mais pleno de "contexto" do que se evidencia na maior parte das discussões sobre escolarização e letramento.

\section{LETRAMENTO NA AMÉRICA DO NORTE URBANA}

Esse tipo de testemunho não está restrito a sociedades nãoeuropéias e rurais: recentes estudos antropológicos dos usos e significados do letramento em contextos urbanos nos Estados Unidos 
Filol. lingüíst. port., n. 8, p. 465-488, 2006.

sugerem que aqui também o letramento fica mais bem compreendido em termos mais amplos do que os empregados dentro da escrita educacional. Camitta (1992), por exemplo, descreve os tipos de textos produzidos por adolescentes fora da escola na Filadélfia urbana e traça um contraste com os textos escolares:

\begin{abstract}
os tipos de textos escritos que desejo estudar não são ensaios, o gênero acadêmico oficialmente estabelecido, mas, antes, aqueles que os adolescentes optam por escrever dentro do quadro da cultura e da organização social adolescente. A esses textos chamarei 'vernaculares', no sentido de estarem mais estreitamente associados com uma cultura que não é nem de elite nem institucional. Por escrita vernacular entendo a escrita que é tradicional e nativa aos diversos processos culturais de comunidades e distinta dos padrões uniformes e inflexíveis das instituições.
\end{abstract}

No contexto escolar, porém, essa escrita tem sido tratada, principalmente em termos morais, como rebelde, como tentativas falhas de letramento adequado, junto com os grafites e outras formas letradas que diferem do modelo de texto ensaístico (cf. Hodges, 1988, sobre grafites).

Camitta trabalhou por três anos com adolescentes na Community High School, Filadélfia, falando acerca de seus escritos e compartilhando as intimidades que isso envolvia. A experiência forçou-a a revisar suposições e crenças sobre a escrita que ela sustentara como professora na escola e que, na sua opinião, são dominantes nos círculos pedagógicos dos Estados Unidos. Gradualmente, ela tomou consciência dos textos e contextos para a escrita não-oficial ou autopatrocinada, praticada pelos adolescentes: a escrita, descobriu ela, era uma atividade importante e variada e identificava grandes áreas que "organizavam" a cultura adolescente. O material escrito incluía letras de rap e notas de ensaio, cartas, diários, páginas de agendas, poemas, rimas e paródias e textos copiados em cadernos. Os jovens estavam "se apoderando" do letramento. O interesse gerado por escrever quando se estava livre das coerções escolares também levava a muito intercâmbio oral entre os alunos, incluindo uma grande quantidade de interação verbal em torno dos textos: podiam ler textos em voz alta uns para os outros, oferecer feedback ou alternar-se na leitura 
STREET, Brian. Perspectivas interculturais sobre o letramento.

silenciosa de textos para comentá-los depois. Camitta conclui que "a colaboração, tanto oral quanto escrita, tal como ocorre no processo de escrita, é um tipo de desempenho em que uma audiência para o texto é atualizada, em vez de ficcionalizada". Além disso, "vimos a escrita ocorrer naquela que tradicionalmente tem sido caracterizada como uma condição de literatura e desempenho orais, isto é, no contexto da comunicação face a face". Em terceiro lugar, ela observou a natureza recursiva desse tipo de escrita: "a performance dos textos ocorria em qualquer ponto do processo de rascunho e a revisão, em consequiência do feedback da audiência, se fazia durante e não depois do rascunho. Esse aspecto de composição pode ser comparado com a improvisação que ocorre durante a performance oral de textos tradicionais". Esses achados têm consideráveis implicações para a análise das práticas orais e escritas, em contextos modernos e tradicionais, para nossas definições de "letramento" e para nossos métodos de estudá-lo. As práticas de letramento de gerações diferentes podem ser tão diferentes quanto as de culturas diferentes. Podem se assemelhar às formas diversas de conhecimento a que se refere Bloch: os indivíduos podem atravessar diferentes estádios de letramento enquanto amadurecem ou podem, como no exemplo de Camitta, alternar entre uma forma e outra de acordo com o contexto.

Shuman (1987) também trabalhou com adolescentes numa Junior High School, num gueto, no Leste dos Estados Unidos. Embora seu interesse, como o de Camitta, estivesse nas narrativas orais e escritas, seu foco particular foram os direitos de contar histórias: na forma escrita padrão, eles envolvem questões de copirraite legal; no contexto dos letramentos vernaculares, os direitos estão embutidos nos relacionamentos e nas interações sociais diários. Shuman investigouos por meio de uma variedade de métodos: viveu em meio a grupos de adolescentes na escola por três anos, gravou em fitas várias conversações, especialmente as narrativas espontâneas, conduziu entrevistas e estabeleceu um questionário com o auxílio dos próprios alunos. Também conseguiu cópias de material escrito, frequientemente em folhas pautadas de caderno, fotocopiou diários e manteve, ela mes- 
Filol. lingüíst. port., n. 8, p. 465-488, 2006.

ma, um Diário Quotidiano (Daily Diary), permitindo aos alunos o acesso às partes que lhes diziam respeito.

Novamente, a relação entre convenções escritas e orais é crucial: "os direitos de contar histórias orais diferem entre as culturas e os grupos, e portanto estão sujeitos a constante mal-entendidos entre as pessoas que operam de acordo com sistemas diferentes". Os direitos em histórias escritas entre os adolescentes urbanos são igualmente complexos, convencionalizados e sujeitos a equívocos. De fato, as histórias que Shuman examina são elas mesmas sobre direitos: elas as descreve como "histórias de brigas numa junior high school, isto é, narrativas de disputas sobre quem tem o direito de dizer o que a quem". Nas comunidades de onde provêm esses adolescentes, é a eles, mais do que a pessoas mais velhas ou mais novas, que se atribui a tarefa de administrar os documentos escritos: eles são intermediários entre a comunidade e o Estado por meio de documentações, preenchimento de formulários, redação de cartas, etc. - outro insightchave sobre os aspectos do letramento intergeracional nessa sociedade. Contudo, os jovens também conservam suas próprias narrativas e diários que registram histórias de brigas e fornecem discursos sobre os direitos de contar histórias dentro de sua comunidade. E usam tanto a fala quanto a escrita para categorizar sua experiência. A teoria geral acerca dos papéis e das associações respectivas da comunicação escrita e oral não funciona em tais contextos: "em contraste com os modelos convencionais que supõem o uso da fala para a comunicação face a face e da escrita para a comunicação do autor ausente, os adolescentes frequientemente usavam narrativas orais para veicular mensagens para terceiras partes ausentes (por meio de boatos do tipo ele-disse-que-ela-disse), e usavam a escrita como parte de trocas face a face nas quais documentos eram produzidos em colaboração e lidos em voz alta, ou como comunicação solitária consigo mesmo em diários". A diferença entre proximidade e distância, e a padronização frequientemente criada pela distância, tinha mais consequiência que a escrita em si mesma. Isso, portanto, sublinha o ponto de que nem toda escrita pertence ao gênero ensaístico e que, não apenas o letra- 
STREET, Brian. Perspectivas interculturais sobre o letramento.

mento, mas também o gênero pode ser um modo importante de distribuir o conhecimento e as atitudes para com textos numa comunidade.

Shuman não avalia os textos dos alunos pelos critérios de competência padronizados na escola, mas, em vez disso, como parte do repertório de uma comunidade única: dessa perspectiva eles representam escolhas entre canais e gêneros de comunicação, mais do que exemplos de maior ou menor deficiência, como o atual debate nos Estados Unidos sobre padrões pareceria requerer. As práticas descritas por Shuman não representam anomalias; ao contrário, elas demonstram "uma necessidade de reavaliar os atuais modelos usados para categorizar a escrita e a fala". A competência comunicativa, portanto, é relativa à comunidade de fala e a suas normas (Dubin, 1989). Labov (1972) e outros demonstraram que há coisas bem mais interessantes nas práticas de linguagem do gueto do que se deduz dos testes padronizados e das opiniões corriqueiras: o trabalho de Shuman, Camitta e outros está revelando agora o rico repertório de práticas escritas, bem como orais, a ser encontrado ali.

Weinstein-Shr (1992) viveu e trabalhou com refugiados Hmong, na Filadélfia, e chama a atenção para aspectos do repertório linguiístico desses novos grupos de imigrantes que também não têm sido reconhecidos pela literatura anterior. A mudança de foco para os estudos de letramento levou-a fazer perguntas novas: "de que modo a vida num ambiente letrado afeta ou muda os relacionamentos sociais?"; "de que modo os relacionamentos sociais influenciam a maneira como o letramento é adquirido e usado?". O letramento é uma inovação relativamente recente para os Hmong, de modo que é possível observar rápidas mudanças à medida que ele é introduzido "em seu repertório de recursos comunicativos". Durante um período de seis anos, Weinstein-Shr conduziu inspeções domésticas e desenvolveu vários "retratos" em profundidade de adultos Hmong na cidade, bem como encontrou-se com certo número deles nas aulas de língua inglesa que ela dava. Examinou os modos como o parentesco e o letramento existiam historicamente para os Hmong e como eles 
Filol. lingüíst. port., n. 8, p. 465-488, 2006.

agora operam em suas novas vidas na Filadélfia urbana. Ela descreve em detalhes as vidas de dois homens e sublinha contrastes em suas maneiras de usar o letramento e de fazer/manter relacionamentos, no contexto da comunidade maior da Filadélfia e de uma discussão geral do letramento e do processo social. Enquanto um homem, Chou Chang, usa o letramento padrão aprendido nas aulas para intermediar entre sua comunidade e os organismos do Estado, num clássico papel de broker*, outro homem, Pao Youa, parece "fracassar" nas aulas formais e, todavia, usa o letramento com considerável habilidade para reforçar aspectos da cultura Hmong tradicional e sua própria autoridade em relação a ela. Chou gasta muito tempo escrevendo cartas a escritórios da Previdência; Pao guarda recortes de jornais em álbuns, coleta materiais de referência e mantém diários pessoais que, reunidos, assumem a autoridade de crônicas, fazendo dele o curador da história e das notícias para sua comunidade. Como os adolescentes de Camitta e Shuman, ele estende o alcance das práticas de letramento para muito além das definições estreitas da escola e da sala de aula. Ambos adaptaram o novo letramento a necessidades atuais, um por meio de novos relacionamentos com as autoridades anfitriãs, o outro construindo formas tradicionais de autoridade. Ambos são mediadores ativos e criativos desse acréscimo ao repertório comunicativo de sua comunidade, não simples recipientes passivos de uma nova tecnologia.

\section{PERSPECTIVAS}

As conclusões de Weinstein-Shr oferecem um resumo adequado dos argumentos aqui apresentados: que o estudo dos significados e usos do letramento nas vidas de pessoas específicas pode oferecer insights gerais sobre a organização humana e o processo social; e que os insights antropológicos podem contribuir para infor-

N. T.: Broker: "intermediário”, "agente”, “cambista”. 
STREET, Brian. Perspectivas interculturais sobre o letramento.

mar a instrução do letramento e a prática educacional à medida que a sociedade contemporânea se torna cada vez mais diversificada culturalmente. Essa abordagem pode nos obrigar a repensar as questões colocadas pela conferência da qual emergiu este livro - "como os padrões de letramento funcional podem ser estabelecidos em contextos variados?", e em vez de perguntar "como podem as demandas locais de letramentos diferentes ser atendidas pelos provedores nacionais e internacionais?". As respostas que emergem do tipo de análise e dados citados acima são também os três temas que propus como a base para o posicionamento deste artigo. Antes de tudo, precisamos primeiramente clarificar e refinar conceitos de letramento, abandonar o grande divisor entre "letramento" e "iletramento" e, em vez disso, estudar as práticas de letramento em contextos culturais e ideológicos diversos. Em segundo lugar, temos de começar onde as pessoas estão, compreender os significados e usos culturais das práticas de letramento e traçar programas e campanhas com base nelas em vez de com base em nossas próprias suposições culturais acerca do letramento. Finalmente, precisamos ligar a teoria do tipo que é desenvolvido nos New Literacy Studies com a experiência e os insights dos profissionais praticantes - professores, facilitadores, animadores que vêm trabalhando no campo do letramento há vários anos e que têm muito a nos ensinar acerca das necessidades e desejos das pessoas nessa área e dos problemas encontrados para atendê-los. Essas três abordagens oferecem, acredito, uma perspectiva mais rica e mais substancial para a política no campo do letramento do que o objetivo de estabelecer "padrões de letramento funcional". A pesquisa e a prática na próxima década dirão se é uma proposta válida.

\section{BIBLIOGRAFIA}

BARTON, D. \& IVANIC, R. (Ed.) (1991). Writing in the community. London: Sage. BAUMANN, G. (Ed.) (1986). The written word. Oxford: Clarendon Press.

BESNIER, N. (1989). Literacy and feelings: the encoding of affect in Nukulaelae letters. Text, 9, 1.

. (1990). Literacy and the notion of person on Nukulaelae. Atoll. American Anthopologist, 93. 
Filol. lingüíst. port., n. 8, p. 465-488, 2006.

BHOLA, H.S. (1984). Campaigning for literacy. Paris: Unesco.

BLEDSHOE, C. \& ROBEY, K. (1986). Arabic literacy and secrecy among the Mende of Sierra Leone. Man, n. 14, p. 4.

BLOCH, M. (Ed.) (1975). Political language and oratory. New York: Academic Press.

. (1989). Literacy and enlightenment. In: SCOUSBOE, K. \& LARSEN, M.T. (Ed.). Literacy and society. Copenhagen: Akademsig Forlag, Centre for Research en Humanities, Copenhagen University.

. (1992). The uses of schooling and literacy in a Zafimaniry village. In: STREET, B. (Ed.). Cross-cultural approaches to literacy. Cambridge: Cambridge University Press.

BLOOME, D. (Ed.) (1989). Classrooms and literacy. Norwood, NJ: Ablex.

BOURDIEU, P. (1976). Systems of education and systems of thought. [Tradução brasileira: BOURDIEU, P. (1982). (Introduçào, Org. e Seleção Sergio Miceli). Sistemas de ensino e sistemas de pensamento. In: A economia das trocas simbólicas. 2 ed. São Paulo, 1982, p. 203-229.]

BOURDIEU, P. \& PASSERON, J. C. (1977). Reproduction in education, society and culture. London: Sage.

CAMITTA, M. (1992). Vernacular writing: varieties of literacy among Philadelphia High School students. In: STREET, B. (Ed.). Cross-cultural approaches to literacy. Cambridge: Cambridge University Press.

CLAMMER, J. (1980). Towards an ethnography of literacy: the effect of mass literacy on language use and social organization. Language Forum, 4, 3.

COOK-GUMPERZ (Ed.) (1986). The social construction of literacy. Cambridge: Cambridge University Press.

COULMAS, F. \& EHLICH, K. (Ed.) (1983). Writing in focus. New York: Mouton.

EAGLETON, T. (1990). Ideology: an introduction. London: Verso.

FINNEGAN, R. (1973). Literacy versus non-literacy: the Great Divide. In: FINNEGAN, R. \& HORTON (Ed.). Modes of thought. London: Faber.

. (1979). Attitudes to speech and language among the Limba of Sierra Leone. Odu, 2.

FINGERET, A. (1983) Social network: a new perspective in independence and illiterate adults. Adult education quarterly, 33, 3, p. 133-4.

FRAWLEY, W. (Ed.) (1982). Linguistics and literacy. Proceedings of the Delaware Symposium on Language Studies. New York: Plenum.

GEE, J. (1900). Social linguistics and literacies: ideology in discourses. Brighton: Falmer Press.

GOELMAN, H.; OBERG, A. \& SMITH, F. (1983). Awaking to literacy. Cambridge: Cambridge University Press.

GOODY, J. (Ed.) (1968). Literacy in traditional societies. Cambridge: Cambridge University Press. Press.

(1977). The domestication of the savage mind. Cambridge: Cambridge University 
STREET, Brian. Perspectivas interculturais sobre o letramento.

. (1986). The logic of writing and the organization of society. Cambridge: Cambridge University Press. Press.

(1987). The interface between the written and the oral. Cambridge: Cambridge University

GRAFF, H. J. (1979). The literacy mith. New York: London: Academic Press.

. (1987). The legacies of literacy. Bloomington, IN: Indiana University press.

GRANT, A. (1986). Defining literacy: common myths and alternative readings. Australian Review of Applied Linguistics.

GRILLO, R. (1989). Dominant languages. Cambridge: Cambridge University Press.

HAMILTON, M. \& BARTON, D. (1985). Social and cognitive factors in the development of writing. In: LOCK, A. \& PETERS, C. (Ed.). The handbook of human symbolic evolution. Oxford: Oxford University Press.

HEATH, S. B. (1982a). What no bedtime story means: Narrative skills at home and at school. Language in Society, 11.

. (1982b). Protean shapes in literacy events. In: TANNEN, D. (Ed.). Spoken and written language: Exploring orality and literacy. Norwood, NJ, Ablex.

. (1983a). Ways with words. Cambridge: Cambridge University Press.

. (1983b). The achievement of pre-school literacy for mother and child. In: GOELMAN, A. H. OBERG \& SMITH, F. Awaking to literacy. Cambridge: Cambridge University Press.

HILL, C. \& PARRY, K. (1988). Ideological and pragmatic models of assessment. Occasional papers, 1, Columbia Univesity Teacher's College. of English language.

HODGES, N. (1988). Language and graffiti: Alternative reading and writing in Milton Keynes. Centre for Languagem and Communication Occasional Paper. Milton Keynes: Open University. HORSMAN, J. (1989). From the learners voice: Women's experience of il/literacy. In: TAYLOR, M.\& DRAPER, J. (Ed.). Adult literacy perspectives. Ontario: Culture Concepts Inc.

KIRKPATRICK, J. (1983). The Marquesan notion of the person. Ann Arbor: Michigan. UMI Research Press.

KULICK, D. \& STROUD, C. (1990). Conceptions and uses of literacy in Papua New Guinean village. Man, 25.

LABOV, W. (1972). Language in the inner city. Philadelphia. University of Pennsylvania Press.

LEVINE, K. (1980). Becoming literate. London: Social Science Research Council. . (1986). The social context of literacy. London: Routledge \& Kegan Paul.

MCCAFFERY, J. \& B. STREET (1988). Literacy research in the UK. Lancaster: RaPAL.

MACE, J. (1979). Working with words. London. Chameleon.

MEEK, M. (1991). On being literate. London: Bodley Head.

MIYOSHI, M. (1988). The "Great Divide" Once Again: Problematics of the Novel and the Third World. Culture and History, 3, Copenhagen. 
Filol. lingüíst. port., n. 8, p. 465-488, 2006.

NYYSTRAND, M. (Ed.) (1982). What Writers Know: the language, process and structure of written discourse. New York: Academic Press.

OGNU, J. (1990). Defining Literacy. In: STIGLER, W. (Ed.). Cross-cultural Psychology.

OLSON, D. (1977). From utterance to text: the bias of language in speech and writing. Harvard Educational Review, 47.

et al. (Ed.) (1985). Literacy, language and learning. Cambridge: Cambridge University Press. 38, 3.

. (1988). Mind and Media: the epistemic functions of literacy. Journal of Communications,

REID, A. (1988). South East Asia in the Age of Commerce; 1450-1680, vol. 1. "The lands below the winds". New Haven and London: Yale University Press.

ROCKHILL, K. (1987a). Gender, language and the politics of literacy. British Journal of the Sociology of Education, 8, 2.

. (1987b). Literacy as threat/desire: longing to be SOMEBODY. In: GASKELL, J. S. \& MCLAREN, A. (Ed.). Women and education: a Canadian perspective. Calgary: Detselig.

SALJO, R. (Ed.) (1988). The Written World: studies in literate thought and action. Berlin, New York: Springer Verlag.

SCOUSBOE, K. \& LARSEN, M. T. (Ed.) (1989). Literacy and Society. Copenhagen University, Akademsig Forlag, Centre for research in the Humanities.

SHUMAN, A. (1983). Collaborative literacy in an urban, multi-ethnic neighbourhood. In: WAGNER, D. (Ed.). Literacy and Ethnicity International Journal for the Sociology of Language, 42, New York: Mouton.

(1986). Storytelling rights: the uses of oral and written texts by urban adolescents. Cambridge: Cambridge University Press.

STREET, B. (1984). Literacy in theory and practice. Cambridge: Cambridge University Press. . (1985). Literacy and orality as ideological constructions: some problems in crosscultural studies. Culture and History, 2.

(1987). Literacy and social change: The significance of social context in the development of literacy programs. In: D. Wagner (Ed.). The future of literacy. Oxford: Pergamon Press.

. (1988). Walter Ong on Literacy. Literacy research center newsletter, 4, 1. Philadelphia: University of Pennsylvania Press.

. (1988). Literacy practices and literacy myths. In: Sljo, R. (Ed.). The written world: studies in literate thought and action. Berlin, New York: Springer-Verlag.

(1990). Putting literacies on the political agenda. Open Letter. Australian Journal for $\overline{\text { Adult Literacy research and Practice, } 1,1 .}$

. (1993). Cross-cultural approaches to literacy. Cambridge: Cambridge University Press.

. (1991). The schooling of literacy. In: BARTON, D. \& IVANIC, R. (Ed.). Writing in the Community. London: Sage.

STUBBS, M. (1980). Language and literacy. London: Routledge \& Kegan Paul. 
STREET, Brian. Perspectivas interculturais sobre o letramento.

TANNEN, D. (1982). The myth of orality and literacy. In: FRAWLEY, W. (Org.). Linguistics and literacy. New York: Plenum Press. p. 37-50. $\overline{\text { Ablex }}$

(Ed.) (1982). Spoken and written language exploring orality and literacy. New Jersey:

WAGNER, D. (Ed.) (1983). Literacy and ethnicity. International Journal of the Sociologyt of Language, 42. New York: Mouton.

; MESSICK, B. \& SPRATT, J. (1986). Studying literacy in Morocco. In: SCHIEFFELIN, B.B. \& GILMORE, P. (Ed.). The acquisition of literacy: Ethnographic perspectives. New York: Ablex.

WEINSTEIN-SHR, G. (1992). Literacy and social process: A community in transition. In: STREET, B. (Ed.). Cross-cultural approaches to literacy. Cambridge: Cambridge University Press.

WERTSCH, J. (Ed.) (1985). Culture, communication and cognition: Vygotskyan perspectives. Cambridge: Cambridge University Press.

WHITEMAN, M. (Ed.) (1981). Writing: the nature, development and teaching of written communication. Vol. 1 Variation in Writing: functional and linguistic and cultural differences. Hillsdale, N.J., Lawrence Erlbaum Associates.

WILLINSKY, J. (1990). The new literacy. London: Routledge. 